\title{
PENGGUNAAN WEARABLE INTERNET OF THINGS (WIOT) OLEH KAUM MILENIAL
}

\author{
Dian Lorinsa, Irwansyah
}

Universitas Indonesia

\begin{abstract}
In this era, the internet and millennial generation are inseparable. The use of the internet of things adopted into wearable devices such as Apple Watch products is interesting to study. This article tries to analyze the extent of the use of the internet of things for Apple Watch users in Indonesia, especially millennial generation. This research article uses a meta-analysis method that reveals previous research related to concept and research objects, which is complemented by observations and interviews with millennials, namely those born in 1980-2000. The results of 18 previous research articles related to the internet of things, wearable devices in millennial generations, have not focuses on the use of wearable devices in this case Apple Watch. The results of interviews with respondents found that the use of Apple Watch is primarily as an alternative and complement to smartphones and used for notification and wearable fast response tools. Apple Watch users have not made maximum use of the technology and health features available.
\end{abstract}

\author{
Keywords \\ Internet of Things, Wearable \\ Devices, Apple Watch, Millenial
}

Correspondence Contact dianlorinsa@gmail.com

\section{PENDAHULUAN}

Dunia kini memasuki era konektivitas digital dan Internet of Things (IoT) telah diaplikasikan di berbagai bidang. Mulai dari penggunaan mesin-mesin automasi yang terintegrasi jaringan internet, pembangunan smart city, pengembangan smart car, dan ciri yang paling menonjol adalah penggunaan masif smart devices seperti smartphone ataupun smartwatch. Di Indonesia kini internet telah menjadi bagian setiap lingkup kehidupan. Hasil riset terbaru Survei Penetrasi \& Profil Perilaku Pengguna Internet Indonesia 2018 oleh Asosiasi Penyelenggara Jasa Internet Indonesia (APJII) diketahui bahwa jumlah pengguna internet Indonesia mencapai 171,17 juta pengguna, atau sebesar 64,8\% dari total populasi penduduk di Indonesia (APJII, 2019: 4). Pengembangan dan penerapan komputer, internet dan teknologi informasi dan komunikasi (TIK) lainnya membawa dampak yang besar pada masyarakat baik dalam manajemen ekonomi, operasi produksi, sosial manajemen dan bahkan kehidupan pribadi. (Q. Zhou dan Zhang, 2011).

Tranformasi terknologi selalu berhubungan dengan perubahan, termasuk gaya hidup. Gaya hidup adalah cara atau karakteristik perilaku dan fungsi individu, kelompok, masyarakat dalam bekerja dan beraktivitas (Zeki, Ramadan, Zeb, dan Ibrahim, 2018). Kecangggihan teknologi diharapkan dapat membawa gaya hidup yang lebih baik, seperti gaya hidup sehat. Gaya hidup sehat adalah cara hidup yang dapat menurunkan resiko sakit atau kematin, serta kesejahteraan fisik, mental, dan sosial (World Health Organization, 2015).

Salah satu teknologi yang mendukung gaya hidup sehat adalah Internet of Things (IoT). Internet of Things (IoT) adalah bentuk interaksi manusia dengan komunikasi yang memudahkan untuk memidahkan data melalui suatu jaringan tanpa interaksi antarmanusia (Khair, 2015). IoT tumbuh dengan cepat dengan perangkat baru yang terhubung setiap saat. Kelompok baru yang muncul dari perangkat ini adalah perangkat yang dapat dipakai (wearable devices) yang kini semakin menarik perhatian semua orang dan berpotensi menjadi komplemen atau pelengkap penting atau bahkan alternatif bagi pengguna ponsel pintar. Kemunculan ponsel pintar telah banyak mengubah cara hidup orang, meningkatkan efisiensi 
kerja dan mendorong perkembangan industri internet seluler yang kuat. Sementara itu, pasar perangkat yang dapat dikenakan atau wearable devices secara bertahap meningkat dan menarik perhatian dari perusahaan besar seperti Google, Apple dan Microsoft. Produk terobosan seperti Google Glass, Apple Watch dan Microsoft Hololens dipromosikan dengan sukses, sedangkan wearable devices dari berbagai kategori telah diluncurkan ke pasaran dan volume pengiriman perangkat telah meningkat secara signifikan (Wen, Zhang, dan Lei, 2017). Pembelian dan pengiriman jam tangan pintar atau smartwatch menurut data Strategy Analytics tahun 2019, secara global mengalami peningkatan pada kuartal keempat 2018, dan Apple Watch menempati urutan teratas sebagai produk smartwatch yang paling diminati. Dalam laporannya (Strategy Analytics, 2019) tercatat Apple menguasai pasar smartwatch dengan market share 51 persen, turun dibandingkan tahun 2017 mencapai hingga 67,2 persen. Ini dikarenakan pesaing Apple, yaitu Fitbit dan Samsung meningkat portfolio smartwatch dan kehadiran ritelnya.

Pengiriman smartwatch global mencatat rekor tertinggi sepanjang masa hingga 45 juta unit sepanjang tahun 2018. Pertumbuhan smartwatch melonjak karena konsumen berusaha untuk mengakses ponsel pintar mereka dan membawa konektivitas digital ke pergelangan tangan. Tren global ini juga melanda Indonesia, dimana kebutuhan akan smartwatch semakin meningkat. Jam tangan pintar kini semakin digandrungi sebagai alternatif pendamping (Mauliansyah dan Mursyidin, 2018). Beberapa argumen dan alasan paling mendasar yaitu terkait fungsionalitasnya dan kemudahan yang ditawarkan. Memiliki fitur-fitur yang berguna, mulai dari notifikasi sampai navigasi peta digital. Merujuk pada preliminary research mengenai pengaruh brand image dan brand trust terhadap niat beli Apple Watch (Kusumo, 2018), didapatkan hasil bahwa $60 \%$ responden yang berumur 18 - 35 tahun, yang termasuk dalam kategori milenial tertarik membeli. Alasan berniat membeli antara lain menganggap bahwa adanya perasaan bangga (gengsi) bila menggunakan perangkat atau produk dari Apple dan beranggapan adanya keyakinan bahwa Apple Watch terpercaya dan handal.

Fokus dalam artikel ini adalah pada pengguna Apple Watch Generasi $Y$ atau milenial yang lahir pada atau setelah 1980-an dan yang memasuki pasar tenaga kerja pada tahun 2000-an. Generasi ini berpendidikan lebih tinggi dari generasi sebelumnya, pengguna yang sangat kompeten pada teknologi informasi dan komunikasi (TIK), serta terbiasa dengan dunia media sosial. Sejauh mana pengaplikasian internet of things melalui penggunaan smartwatch oleh generasi milenial di Indonesia sangat menarik untuk dikaji. Melalui analisis tentang smartwatch (Abdullah, 2015) ditemukan bahwa pria lebih tertarik membeli arloji Apple daripada wanita. Bahkan, pria berusia antara 18-24 memiliki persentase angka paling tinggi sebesar 26\% lebih tertarik membeli Apple Watch, dan wanita di range usia yang sama yaitu 18-24 lebih tidak tertarik membeli Apple Watch menunjukkan persentase hanya 9,5\%. Kelompok milenial wanita disimpulkan harus melakukan upaya lebih untuk belajar tentang penggunaan Apple Watch (Thompson, 2015).

Artikel ini mencoba untuk melakukan analisis terhadap penelitian terdahulu mengenai wearabale devices dan Apple Watch untuk mengetahui sejauh mana pemanfaatan internet of things bagi pengguna Apple Watch di Indonesia khususnya generasi milenialnya. Penelitian tentang wearable devices dan Apple Watch lebih banyak berfokus pada strategi pemasaran dan faktor pengaruh pembelian produk Apple Watch, pemanfaatan wearable devices bagi kesehatan dan teknologi yang disematkan pada wearable devices. Studi dan penelitian terdahulu terkait artikel ini akan disajikan dalam bagian temuan dan diskusi sebagai hasil meta analisis. 


\section{KAJIAN TEORITIK}

\section{Internet of Things}

Internet of Things (IoT) adalah pengembangan dari pengertian sebelumnya tentang komputasi di mana-mana, komputasi luas dan kecerdasan. Di sini, ada perkembangan penting sebagai "dimensi sebelumnya internet umum - dari kapan saja, konektivitas di mana saja untuk siapa saja - adalah ditambah dengan dimensi apa pun" (Nolin dan Olson, 2016).

Sejarah pengembangan IoT dimulai pada tahun 1989, sejak istilah internet diperkenalkan dan meluas ke penjuru dunia (Malik, Magar, Verma, Singh, dan Sagar, 2019). Pengembangan internet didukung dengan upaya para peneliti mengaitkan segala kegiatan manusia dalam bentuk digital. Pada tahun 1990, John Romkey merancang perangkat internet pertama, dimana pemanggang roti yang dapat diaktifkan dan dinonaktifkan dengan internet. Steve Mann mengembangkan Wearcam pada tahun 1994 dengan memanfaatkan 64 sistem prosesor secara bersamaan. Pada tahun 1997, Paul Saffo memberikan deskripsi singkat pertama tentang sensor dan tindakannya di masa depan. Pada tahun 1999, Kevin Ashton mengenalkan Internet of Things, Managing Director Auto-Id Center di MIT. Mereka juga membentuk sistem berbasis RFID untuk identifikasi objek di seluruh dunia. Seiring waktu, gagasan ini muncul dan sangat diperluas. Interpretasi asli merujuk pada kesempatan untuk mengidentifikasi objek dengan tag radio atau barcode. Ini memungkinkan agregasi internet katalog memungkinkan seseorang untuk melihat di mana objek individu berada.

Seperti yang didefinisikan oleh Sundmaeker, dkk. (2010), IoT adalah infrastruktur jaringan global yang dinamis dengan kemampuan konfigurasi sendiri berdasarkan protokol komunikasi standar dan interoperable di mana fisik dan 'benda' virtual memiliki identitas, atribut fisik, dan kepribadian dan penggunaan virtual interface cerdas, dan terintegrasi dengan mulus ke dalam jaringan informasi.

Rujukan sumber lain mengatakan, IoT umumnya merujuk pada infrastruktur global yang dibangun dan berkembang pada masyarakat informasi cepat, dimana teknologi ini memungkinkan layanan dengan menghubungkan hal-hal fisik dan virtual menggunakan teknologi informasi dan komunikasi interoperable yang ada dan terus berkembang (Rekomendasi ITU, 2014). IoT hadir dan secara dramatis mengubah kehidupan orang-orang, tempat kerja, produktivitas dan konsumsi. Sederetan bisnis baru akan muncul sebagai hasilnya (Shin dan Jin Park, 2017), salah satunya pengembangan wearable devices.

\section{Wearable Devices}

Merupakan perangkat yang dapat dipakai yang sangat beragam dan memiliki fungsi yang kaya dan pengalaman pengguna. Saat ini, perangkat yang dapat dikenakan (wearable devices) utamanya mencakup jam tangan pintar (smartwatch), perangkat pemantauan latihan fisik, perangkat realitas virtual (virtual reality) dan kacamata pintar (smart glasses). Apple Watch merupakan salah satu dari perangkat yang dapat dipakai (wearable devices) yang independent atau melekat pada smartphone, dan dapat berinteraksi melalui tampilan di pergelangan tangan, dengan ekspansi dalam sejumlah aplikasi melalui instalasi berbagai jenis aplikasi yang berada dalam ekosistem ponsel pintar (Wen, dkk., 2017).

Wearable devices mengacu pada istilah wearable computing karena kemampuan komputasi diperlengkapi pada perangkat tersebut. Wearable computer pertama kali ditemukan oleh Ed Thorp dan Claude Shannon di 1966 berupa komputer analog seukuran kotak rokok yang digunakan untuk menebak roda roullette. Setahun setelahnya, Hobert Upton membuat wearable analog computer yang digunakan di mata untuk membantu membaca bahasa bibir (Siradj, 2016). 
Perangkat yang dapat dikenakan atau wearable devices menjadi topik hangat kini, seperti yang diilustrasikan oleh tantangan baru $\$ 5.000$ "Make It Wearable" baru-baru ini, yang dikeluarkan oleh Intel. Tantangan ini akan menghadiahi visioner dan pembangun yang menyusun atau membangun aplikasi yang dapat dipakai (wearable) yang dapat mengubah komputasi personal ke arah inovatif baru (mouser, 2019). Perangkat yang dapat dikenakan atau wearable devices sekarang menjadi jantung dari hampir setiap diskusi yang terkait dengan Internet of Things (IoT), dan berbagai kemampuan baru yang dapat dibawa oleh konektivitas yang dapat ditembus. Untuk saat ini, jam tangan pintar dan perangkat yang dapat dikenakan dalam bentuk lainnya akan terus mendukung kebugaran dan fitur yang berhubungan dengan kesehatan. Namun, seiring perkembangan teknologi dan kemampuan, produk yang dapat dikenakan (wearables) akan menjadi fitur yang lebih menonjol dalam vertikal industri. Melihat peluang ke depan, perangkat yang dapat dikenakan (wearable devices) akan menjadi kontributor utama untuk memajukan teknologi IoT. International Data Corporations (IDC) memprediksi produk yang dapat dikenakan akan memainkan peran penting dalam evolusi teknologi augmented reality (idc.com, 2019).

\section{Wearable Internet of Things (WIoT)}

Dengan menggunakan IoT muncul solusi khusus terkait aplikasi dengan menghubungkan objek fisik dengan internet dan hadirnya kolaborasi satu sama lain untuk mencapai tugas yang diberikan. Perangkat wearable yang saling berhubungan untuk pelacakan aktivitas fisiologis bermunculan dengan cepat dan membentuk segmen baru yang disebut Wearable IoT (WIoT) (Kumari, Lopez-Benitez, Lee, Kim, dan Minhas, 2017).

Wearable Internet of Things (WIoT) adalah infrastruktur teknologi yang menghubungkan sensor yang dapat dikenakan untuk memungkinkan pemantauan faktor manusia termasuk kesehatan, kebugaran, perilaku, dan data lain yang berguna dalam meningkatkan kualitas hidup individu sehari-hari (Hiremath, Yang, dan Mankodiya, 2014).

\section{Smartwatch}

Smartwatch bisa memainkan peran kecil perangkat komputasi genggam, seperti smartphone (Jung et al., 2016), dapat juga memainkan peran jam tangan tradisional. Jam tangan pintar atau smartwatch mengacu pada jam tangan yang terkomputerisasi dengan fungsi asisten digital pribadi serta pencatat waktu (Edwards, 2013). Perangkat pintar ini adalah perangkat elektronik interaktif terhubung ke perangkat atau jaringan lain (Privat, 2000). Selain itu, smartwatch secara otonom merupakan perangkat digital atau fisik yang dilengkapi dengan fungsi seperti penginderaan, komunikasi dan memberikan informasi yang bermanfaat bagi pengguna seperti detak jantung, berita, cuaca, dan lokasi seseorang, peringatan informasi, email, pesan dan media sosial (Kortuem, dkk., 2010).

Sebuah terobosan baru diwujudkan dalam smartwatch dimana wujud komputer lebih kecil yang terjangkau dan portable. Ada dua perusahaan jam tangan pintar terkenal yang kebanyakan orang gunakan yaitu Samsung, Apple, Fitbit dan XiaoMi, dan semuanya memproduksi perangkat pribadi seperti tablet, telepon, dan banyak lainnya. Perusahaan Apple menyediakan berbagai produk untuk dan bisnis dengan integritas dan kualitas tinggi. Produk yang disediakan untuk pengguna sangat menarik dan juga dibutuhkan dalam kehidupan sehari-hari. 
Apple Watch

Apple Watch merupakan salah satu dari sekian banyak smartwatch yang diluncurkan ke pasaran. Apple Watch adalah produk yang sukses di mana Tim Cook, CEO Perusahaan Apple, mengatakan bahwa pendapatan jam tangan ini mencapai sekitar $\$ 1$ miliar dalam penjualan di seluruh dunia. Selain itu, produk ini memiliki banyak fungsi hampir seperti ponsel pintar. Arloji ini memiliki desain yang kuat dan Apple memiliki lebih banyak penelitian hingga berkontribusi pada tingkat kepuasan pelanggan Apple yang tinggi dengan menjadikan arloji ini plain dan simple (Kharpal, 2015).

Hampir semua produk Apple memiliki arsitektur dasar yang sama merujuk pada ide konsistensi. Karena itu, pengguna saat ini telah memiliki ide bagus tentang apa yang akan mereka ketahui cara mengoperasikan jam tangan Apple sebelum mereka membeli, dengan mudah karena produk Apple menggunakan sistem operasi iOS dan mereka akan mudah mengadopsi dengan Apple Watch baru sehingga ini membuat pengguna berulang untuk membeli produk baru. Oleh karena itu, Apple Watch berbeda dan memberikan nilai kepada pelanggan (Crothers, 2015).

Apple Watch adalah perangkat elektronik pribadi yang menggabungkan pengguna watchOS antarmuka dan teknologi yang dibuat khusus untuk perangkat yang lebih kecil, memasukkan Digital Crown $^{\mathrm{TM}}$, alat navigasi unik yang memungkinkan pengguna untuk secara mulus menggulir (scroll), memperbesar dan menavigasi, dan Force Touch, teknologi yang merasakan perbedaan antara ketukan dan tekanan dan memungkinkan pengguna untuk mengakses kendali didalam aplikasi. Apple Watch memungkinkan pengguna untuk berkomunikasi dalam cara baru dari pergelangan tangan mereka, melacak kesehatan dan kebugaran pengguna melalui aktivitas dan aplikasi latihan, dan termasuk Siri dan Apple Pay. Pada bulan September 2017, Apple Inc memperkenalkan Apple Watch Series 3, yang memasukkan fitur kesehatan dan peningkatan kebugaran dan kemampuan seluler bawaan pada perangkat yang memenuhi syarat (Apple, 2017). Dan pada Desember 2018, diluncurkan Apple Watch series 4. Apple Watch generasi keempat ini menghadirkan desain dan pengembangan Apple Watch secara fundamental. Digital Crown yang dimaksudkan untuk menyediakan cara mudah dalam menavigasi Apple Watch tanpa harus mengutak atik layar, dalam Apple Watch Series 4 ini, mekanismenya dikembangkan secara total, feedback berupa getaran begitu presisi, seperti klik selagi pengguna menggulir (scrolling) (Apple.com, 2019).

Fitur pelacakan kesehatan seperti sensor jantung optik sudah menjadi bagian dari Apple Watch sejak awal, memungkinkan pengguna untuk memeriksa detak jantung dengan cepat. Kini, sensor tersebut juga mampu medeteksi jika detak jantung turun ke bawah ambang batas yang ditetapkan selama 10 menit ketika pengguna sepertinya tidak banyak bergerak, memicu pemberitahuan detak jantung rendah.

Chip S4 pada Apple Watch Series 4 lebih dari sekadar prosesor, yang merupakan System in Package (SiP) lengkap, dengan keseluruhan sistem yang dibangun dalam satu komponen. Arsitektur ini memungkinkan Apple Watch memasukkan berbagai kemampuan luar biasa ke dalam ruang yang kecil. CPU di generasi keempat Apple Watch juga lebih cepat dimana aplikasi terbuka dengan lebih cepat dan performa kian meningkat di seluruh sistem.

\section{Generasi Milenial}

Pengertian generasi dari rujukan Guha (2010) merupakan kelompok yang dapat diidentifikasi dan dikenali dari tahun kelahiran, umur, dan peristiwa penting yang membentuk kepribadian mereka. Generasi manusia dapat dikembangkan oleh peristiwa yang mengubah peradaban yang sangat berpengaruh seperti perang, penemuan pada pengembangan teknologi baru, atau 
transisi besar situasi ekonomi. Berdasarkan rujukan, ada tiga generasi yang kini eksis dan mendominasi yaitu dikenal dengan istilah Baby Boomer, Generasi X, dan Milenium atau Milenial (Kaifi, 2012). Generasi terbaru yang kini eksis dan memasuki dunia bisnis dan pekerjaan adalah generasi Milenial, yaitu mereka yang lahir antara 1980 dan 2000. Mereka disebut Milenium atau milenial karena kedekatan mereka dengan era milenium baru dan dibesarkan di zaman yang lebih digital (Kaifi, 2012). Generasi ini dipengaruhi oleh perkembangan komputer dan penerimaan terhadap keluarga dan nilai non-tradisional (Andert, 2011). Generasi Milenial menikmati memanfaatkan teknologi. Generasi milenial menjadi tergantung pada teknologi di usia yang lebih awal dari generasi lain.

Bagi milenial, penggunaan teknologi dan media sosial adalah alami dan penting (Mauliansyah, 2016). Karena ini, milenial tidak hanya membutuhkan penggunaan teknologi yang kuat di keseharian, tetapi juga harus memilikinya dalam bentuk portable (Bannon, dkk., 2011). Sayangnya, penggunaan teknologi juga memberikan nilai negatif dalam generasi milenial karena mereka selalu mengharapkan untuk memiliki segalanya serba instan (Behrens, 2009; Cahill dan Sedrak, 2012). Dengan kecepatan internet yang menyediakan akses instan ke jawaban apa pun, generasi ini sekarang mengharapkannya memiliki jawaban dan umpan balik atau feedback instan (DeVaney, 2015).

\section{METODOLOGI}

Untuk menggambarkan pengalaman milenial sebagai pengguna Apple Watch, penulis menggunakan pendekatan kualitatif. Pendekatan kualitatif digunakan untuk mendeskripsikan suatu kejadian sosial yang dijabarkan secara spesifik, agar pembaca memahami keunikan di luar kejadian yang bersifat umum (Denzin dan Lincoln, 2008).

Data dalam penelitian ini terbagi menjadi dua, yaitu primer. Data primer dalam penelitian ini dikumpulkan dengan menggunakan pendekatan kualitatif berbasis teks, yaitu menggunakan meta analisis dan dilengkapi dengan wawancara kepada informan. Wawancara penelitian kualitatif akan mendapatkan wawasan melalui percakapan, jadi tidak hanya tingkat makna konten yang digambarkan, tetapi tingkat hubungan disampaikan juga. Metodologi ini berguna dalam memahami pengalaman pengguna, memungkinkan pewawancara untuk mendapatkan tanggapan mendalam terhadap pertanyaan (McNamara, 2007). Metode kualitatif untuk melakukan wawancara mendalam menyediakan penelitian dengan detil informasi tentang pemikiran individu dan perspektif penggunaan Apple Watch dalam kehidupannya. Data sekunder dikumpulkan dari artikel, buku, dan data lainnya yang didapatkan dari penelitian terdahulu.

Penelitian ini dilakukan di sebuah instansi di Jakarta. Purposive sampling digunakan dalam penelitian ini sebagai teknik pengumpulan informan. Informan adalah pekerja wanita milenial, yaitu mereka yang lahir tahun 1980-2000 atau yang sekarang berumur 19 hingga 39 tahun dan merupakan pengguna Apple Watch dalam aktivitasnya. Penulis memilih 4 (empat) orang informan yang dinilai telah memenuhi kriteria informan dalam penelitian ini. Informan selanjutnya dituliskan dengan inisial W, X, Y, dan Z.

Untuk menguji keabsahan data, penulis melakukan triangulasi pada sumber dan teknik penelitian. Pencocokan data antar informan dilakukan sebagai triangulasi sumber. Kemudian membandingkan hasil wawancara dengan studi terdahulu dilakukan sebagai triangulasi teknik penelitian. 


\section{HASIL DAN PEMBAHASAN}

\section{Internet of Things dan Generasi Milenial}

Sebagai digital native, generasi Milenial seharusnya berpotensi memiliki eksposur dan akses yang lebih besar ke perangkat internet dan menjadi pasar besar bagi produk-produk IoT (Strother, 2017). Namun kenyataan di lapangan menunjukkan hasil yang bertolak belakang dengan beberapa penelitian oleh beberapa Lembaga survey, seperti KPMG dan Association of Energy Services Professionals (AESP). Rendahnya penggunaan perangkat IoT oleh generasi Milenial dikarenakan dua alasan, yaitu:

\section{Lack of homeownership}

Pada saat ini dibandingkan Milenial, Generasi X dan Baby Boomers kebanyakan menjadi pemilik tertinggi dalam suatu keluarga. Hal ini menjadi faktor utama yang menjadikan mereka menentukan apa saja yang ingin dimiliki, termasuk perangkan IoT. Selain itu generasi Milenial lebih memilih untuk menyewa properti secara sementara dibandingkan memanfaatkan teknologi baru untuk efisiensi energi dan keberlanjutan di rumah.

Hasil penelitian menunjukkan bahwa penggunaan teknologi IoT belum sepenuhnya dilakukan meski informan menjadi pemilik (ownership) di rumah atau keluarganya karena biaya yang dikeluarkan cukup besar dan memanfaatkannya hanya untuk alat yang benar-benar dibutuhkan seperti smart phone dan smart watch sebagai pelengkap.

"Jika menuntut ideal, tentu akan lebih efisien dan efektif untuk pakai perangkat teknologi seperti IoT di setiap komponen rumah. Namun biayanya sangat besar, di Indonesia mungkin alatnya telah tersedia, tetapi untuk perbaikan dan maintainacenya masih kurang. Akhirnya untuk saat ini cukup alat-alat yang sesuai kantong dan sering digunakan" (W, wawancara, 15 Agustus 2020)

\section{Concerns over IoT security}

Hampir 75\% Milenial yang disurvei oleh KPMG mengindikasikan bahwa mereka cenderung menggunakan lebih banyak perangkat IoT jika mereka lebih yakin bahwa perangkat tersebut aman. Sebagai generasi yang tumbuh dengan dikelilingi teknologi internet, generasi Milenial memilki pemahaman yang lebih mengenai bahaya perangkat-perangkat internet yang tidak memiliki kepastian keamanan.

Namun hasil penelitian ini menunjukkan bahwa kepercayaan kepada merek (brand) perangkat IoT membuat perhatian pengguna terhadap keamanan tidak menjadi masalah. Informan percaya bahwa perangkat dari Apple dapat dipercaya terkait keamanan data dibandingkan produk lain.

"Untuk perangkat Apple sendiri, selama bertahun-tahun pakai belum pernah menemukan kejadian pembobolan data atau masalah keamanan dan privasi. Aku sendiri, karena Apple agak ribet dihubungkan kemana-mana, hal itu yang malah membuat perangkatnya aman." (Z, wawancara, 15 Agustus 2020)

\section{Internet of Things Bagian Dari Gaya Hidup}

Penerapan IoT sangat banyak dan beragam di berbagai bidang dan telah menjadi bagian kehidupan sehari-hari individu yang secara luas mencakup masyarakat, industri, dan lingkungan. Menurut Internet of Things Strategic Research Agenda (SRA) (Bhuvaneswari dan Porkodi, 2014), pada tahun 2010 terdapat enam atau lebih domain pengaplikasian IoT, yaitu 
energi pintar, kesehatan pintar, bangunan pintar, transportasi cerdas, kehidupan cerdas, dan kota pintar. Selain itu survey tambahan dilakukan pada tahun 2010 yang menunjukkan adanya 65 skenario aplikasi IoT diidentifikasi dan dikelompokkan ke dalam 14 domain, yaitu transportasi, rumah pintar, kota pintar, gaya hidup, retail, pertanian, pabrik pintar, pemasok, keadaan darurat, perawatan kesehatan, interaksi pengguna, kebudayaan dan pariwisata, serta lingkungan dan energi.

Pada industri mode dan gaya hidup melakukan peralihan ke IoT untuk meningkatkan pengalaman konsumen dengan menanamkan teknologi dalam produk yang mencakup jam tangan, kaos, sepatu, atau hampir semua artikel pakaian (Dassault Systèmes, 2017). Penerapan IoT pada industri mode dan gaya hidup berkaitan dengan hadirnya konsep smart product. Produk pintar (smart product) adalah produk apa pun yang didalamnya disematkan komponen teknologi dan konektivitas dengan untuk tujuan menghadirkan fungsionalitas baru yang melampaui batasan produk tradisional dan fisik. Bentuk smart product dalam industri mode dan gaya hidup hadir dalam dua bentuk, yaitu peralatan olahraga dan kebugaran dengan tingkat penetrasi tinggi yang berfungsi sebagai pelacak kebugaran atau aktivitas dan pelatih pribadi; busana yang lembut dan aksesoris yang dapat memainkan peran estetika atau hal berguna lainnya.

Hasil penelitian menunjukkan bahwa setiap informan setidaknya telah memiliki lebih dari dua perangkat IoT yang mereka manfaat dalam aktivitas mereka, seperti perangangkat rumah tangga dan alat elektronik, terutama smartphone dan smart watch sebagai pelengkapnya. Sebelumnya, informan menjelaskan bahwa biaya yang tinggi dan ketersediaan jasa perbaikan perangkat di Indonesia belum mendukung seperti di luar negeri, menjadi alasan bagi mereka belum maksimal menggunakan perangkat IoT di rumah.

\section{Gaya Hidup Sehat Milenial}

Melihat tren anak muda atau generasi milenial, tren kesehatan dan kebugaran menjadi salah satu prioritas dalam gaya hidup keseharian. Menurut data yang dilansir dari womenmarketing.com, gaya hidup kesehatan dan kebugaran menempati posisi kedua dalam kehidupan milenial dan setelah itu prioritasnya adalah keluarga. Milenial membawa kebugaran ke dalam keseharian mereka. Kini tren gaya berpakaian atletik tidak hanya dikenakan dalam aktivitas olahraga, melainkan dalam keseharian seperti penggunaan sneaker, keterlibatan dalam berbagai acara olahrga seperti lari dan postingan di media sosial pribadi.

Menghadirkan smart watch sebagai pelengkap penampilan dan teknologi portable yang memiliki konektivitas dengan ponsel pintar mereka juga menjadi salah satu tren dan pilihan menarik bagi milenial kini. Dari hasil observasi, banyak milenial yang menampilkan gaya hidup sehat di media sosial mereka, seperti menghabiskan waktu di pusat kebugaran, mengikuti ajang lari maraton, hingga mengonsumsi produk organik, kian bermunculan akun dan tokoh yang membagikan berbagai informasi terkait kesehatan dan kebugaran yang banyak diikuti oleh anak muda generasi milenial. Terbukti berdasarkan riset yang dilakukan oleh Nielsen's Global Health \& Wellness Survey, sebanyak 81\% generasi milenial mau membayar lebih untuk makanan yang memiliki label sehat. Di Indonesia sendiri, menurut survei yang dilakukan oleh womensmarketing.com, sebanyak $53 \%$ generasi milenial menjadikan gaya hidup sehat sebagai prioritas.

Hasil penelitian menunjukkan bahwa informan memiliki perhatian dengan kondisi mereka yang telah berubah dan memberikan dampak besar bagi kesehatan. Seluruh informan menyatakan bahwa mereka telah melakukan setidak satu upaya untuk membentuk gaya hidup sehat, seperti melakukan kegiatan olahraga seminggu atau sebulan sekali. Aktivitas gaya hidup sehat yang dipilih juga terbioang mudah, serta tidak memakan banyak waktu dan biaya, 
seperti jogging, senam, dan muang thai. Informan akan melakukan usaha gaya hidup lebih apabila diberikan secara gratis, seperti mendapat fasilitas dukungan dari kantor.

\section{Apple Watch sebagai Bentuk Internet of Things}

Internet of Things (IoT) adalah gabungan konteks yang terdiri dari sensor, informasi, lokasi, dan aktivitas, yang tersebar di berbagai perangkat yang saling berkolaborasi (Gruman, 2014).

\section{Sensors}

Sensor merupakan salah satu komponen Internet of Things (IoT) yang berfungsi mengumpulkan data untuk keputusan yang lebih cerdas (te.com, 2020). sensor dalam IoT disebut dengan WBAS. Menurut Hiremath, Yang, dan Mankodiya (2014) Wearable body area sensors (WBAS) adalah komponen utama yang tidak mencolok menyelimuti tubuh untuk menangkap data yang berpusat pada kesehatan. WBAS memiliki dua fungsi , yaitu:

a. Mengumpulkan data baik secara langsung dari tubuh melalui sensor kontak atau dari sensor periferal yang memberikan informasi tidak langsung tentang tubuh dan perilakunya.

b. Menyiapkan data untuk orientasi analisis sebagai umpan balik secara terus menerus atau transmisi jarak jauh untuk analisis komprehensif dan menghasilkan keputusan.

Sebagai salah satu bentuk IoT, Apple Watch juga memanfaatkan sensor sebagai alat untuk membaca kondisi tubuh penggunanya, seperti Optical Heart Sensor (PPG), Electrical Heart Sensor (Electrodes), dan Next Generation Accelerometer and Gyroscope (Apple.com, 2020a). Ketiga sensor tersebut berfungsi untuk memberikan pemberitahuan terkait denyut jantung (tinggi, rendah, dan irama yang tidak teratur), klasifikasi fibrilasi atrium dan irama sinus, serta kondisi jatuh atau tumbang.

\section{Information}

Informasi menjadi bagian penting dalam konsep IoT. IoT hadir sebagai media yang berfungsi saling menghubungkan, memberi umpan balik, dan berbagi informasi dalam membantu individu menjalani kegiatan secara cerdas (efisien dan efektif) (Avystem.com, 2019).

Dalam Apple Watch, informasi dihadirkan dalam bentuk pemberitahuan (notification). Pemberitahuan (notification) mengomunikasikan informasi bernilai tinggi melalui interaksi cepat dan mudah dilihat (Apple.com, 2020b). Pemberitahuan dalam Apple Watch terjadi dalam dua tahap, yaitu tampilan pendek dan tampilan panjang. Tampilan singkat (short looks) berisi informasi singkat tetapi bermakna dengan muncul saat pergelangan tangan pemakainya diangkat dan menghilang saat diturunkan. Sementara tampilan panjang (long looks) muncul ketika perngelangan tangan tetap terangkat dan informasi diberikan secara lebih detil.

\section{Location}

Lokasi adalah dimensi penting dari konsep IoT yang mencakup kemampuan benda untuk merasakan dan mengomunikasikan posisi geografisnya (Lundquist, 2016). Dalam konteks ini, lokasi bertindak sebagai prinsip pengorganisasian untuk semua hal yang terhubung ke Internet. Pembatasan lokasi memberikan penyaringan (filter) terhadap informasi atau data dalam internet yang dibutuhkan oleh pengguna. IoT menanamkan konsep teknologi global positioning systems (GPS) sebagai alat bagi penggunanya memanfaatkan informasi internet terkait dengan lokasi.

Apple mulai menerapkan sistem GPS pada Apple Watch Series 2, 3, 4, dan yang terbaru 5 (Chan, 2019). Apple Watch dengan GPS di dalamnya dapat memanfaatkan fitur seluler saat tidak terhubung dengan iPhone yang dipasangkan atau jaringan Wi-Fi. Selain itu, GPS dalam Apple Watch biasanya dimanfaatkan untuk melacak program Latihan, seperti jalan-jalan, lari, berenang dan siklus di luar ruangan (Cipriani, 2017). 


\section{Activities}

Internet of Things (IoT) dapat mengubah gaya hidup manusia. Potensi integrasi konsep IoT dapat memberikan beberapa manfaat untuk meningkatkan kualitas hidup individu dan membuktikan saran gaya hidup yang lebih sejahtera (Rghioui dan Oumnad, 2017). Peningkatan kualitas hidup sebagai salah satu bentuk IoT diterapkan Apple Watch dalam Activity Monitor. Activity monitor berfungsi melacak seberapa banyak pengguna melakukan pergerakan, berolahraga, dan berdiri dari hari ke hari (Support.apple.com, 2020).

\section{Apple Watch sebagai Bentuk Wearable Devices}

Sebagai perangkat yang dapat dikenakan (wearable devices) yang ditujukan untuk satu pengguna, Apple Watch adalah sumber pengalaman sehari-hari. Ini adalah perangkat hybrid yang beroperasi sebagai peta, mainan, game, alat, dan aksesori mode. Perangkat ini memediasi kehidupan setiap hari dari gaya pribadi ke kesehatan dan kesejahteraan (Lupton, 2014), dari manajemen tidur hingga komunikasi antarpribadi. Ini hibridisasi tidak hanya elemen 'nyata' dan 'virtual' tetapi juga elemen pengalaman sehari-hari yang sebelumnya mungkin tampak sangat terpisah (bekerja dan bersantai adalah dua contoh utama). Sebagai antarmuka, Apple Watch tidak hanya menghubungkan kita dengan orang lain, tetapi juga mengharuskan kita untuk berinteraksi dengannya (melalui sentuhan, detak jantung, gerakan, dan suara) untuk mengumpulkan dan menghasilkan data agar dapat berhubungan dengan dunia. Seperti hubungan pribadi antara individu, tubuh mereka dan struktur perangkat mereka adalah pertemuan yang unik untuk setiap pengguna. Itu dibentuk oleh elemen-elemen yang terletak seperti tempat dan lokasi (Wilken, 2014), serta sentuhan, dan interaksi penginderaan lainnya antara pengguna dan teknologi (Cranny-Francis, 2007).

\section{Faktor Generasi Milenial Memilih Apple Watch}

\section{Kegunaan (Usability)}

Nilai kegunaan atau usability adalah nilai penggunaan atau utilitas dari jam smart watch untuk memenuhi kebutuhan konsumen (Anggraini, Kaburuan, Wang, dan Jayadi, 2019). Studi terdahulu tentang penggunaan smart watch telah dilakukan oleh Chen, dkk. (dalam Anggraini, Kaburuan, Wang, dan Jayadi, 2019) yang diteliti secara kualitatif dengan wawancara mendalam. Hasil penelitian Chen menunjukkan bahwa kegunaan smart watch adalah untuk memeriksa notifikasi, pemutar music dan pemeriksa cuaca. Namun, tampilan layar smartwatch yang kecil memberikan umpan balik yang kurang baik bagi pengguna untuk melihat konten secara visual.

Informan menyatakan bahwa aktivitas mereka yang tinggi dengan ponsel (iPhone) mereka, menjadi salah satu dorongan untuk membeli Apple Watch sebagai perangkat pendukung kerja. Fitur seperti notifikasi; pembaca pesan, email, dan foto; siri (alarm, pengingat); serta menerima telepon sangat berguna dalam membantu pekerjaan mereka ketika malas melakukan kontak dengan ponsel mereka.

"Sering kali tertalu fokus kerja, ponsel sedang di-charge, notifikasi telat untuk diketahui. Bagi saya Apple Watch nggak cuma sekedar untuk gaya dan bawa nama brand. Tetapi memang bermanfaat sekali untuk remainder dan terhubung dengan perangkat Apple lainnya." - Y.

Dengan adanya fitur Health dan Workout pada Apple Watch menjadi kegunaan tambahan yang mendorong pengguna untuk melkukan kegiatan yang terkait dengan gaya hidup sehat. 
"Meski agak jarang dipakai, tetapi kan penasaran dengan fungsi yang tersedia. Akhirnya kadang-kadang ngetes fitur-fitur tersebut cara kerjanya bagaimana." - Y.

\section{Merek (Brand)}

Merek (brand) dapat didefinisikan sebagai sekumpulan atribut berwujud dan tidak berwujud yang dirancang untuk menciptakan kesadaran dan identitas, dan untuk membangun reputasi produk, layanan, orang, tempat, atau organisasi (Sammut-Bonnici, 2015). Dalam penelitian sebelumnya, kepuasan terhadap suatu merek telah terbukti berpengaruh pada loyalitas merek (Anggraini, dkk., 2019). Hal ini meningkatkan kemungkinan mengadopsi produk baru dari merek yang disukai dan mengurangi kemungkinan mengadopsi produk baru dari merek lawan, meski produk baru pesaing adalah yang pertama memasarkannya.

Pemilihan Apple Watch sebagai alternatif dan pelengkap bagi ponsel membantu pengguna dalam aspek hidupnya. Bentuk Apple Watch yang menarik dan artistik juga menjadi daya tarik tersendiri bagi pengguna Apple Watch. Pemilihan Apple Watch juga karena faktor kesamaan dan kemudahan sinkronisasi dengan sistem ponsel yang dimiliki yaitu iPhone dan sistem iOS. Serupa dengan hasil penelitian yang telah dilakukan Anggraini, dkk. (2019), penelitian ini juga menunjukkan bahwa loyalitas dan kepercayaan informan pada merek menjadikan mereka penggemar setiap produk Apple.

"Aku pakai iPhone, karena merek Apple ribet hanya mau dihubungkan dengan merek yang sama, tentu untuk pilihan smart watch, aku pilih Apple Watch. Selain itu tampilan Apple Watch cocok dan lebih kalsik menurutku." - X.

"Jujur aku penggemar setiap produk Apple, jadi kalo harus pilih smart watch ya langsung Apple Watch. Karena aku rasa kualitas Apple lebih baik dibandingkan produk lain." - Z.

\section{Harga (Pricing)}

Harga (price) menjadi salah satu atribut dalam penilaian konsumen, harga yang lebih tinggi biasanya mengurangi keinginan konsumen untuk membeli produk (Jung, dkk, dalam Anggraini, dkk., 2019). Serupa dengan hasil penelitian yang dilakukan oleh Anggraini, dkk. (2019), informan menunjukkan bahwa harga menjadi perhatian mereka dalam membeli smart watch. Pengguna Apple tentu akan memilih Apple Watch sebagai pilihan smart watch agar mudah melakukan sinkronasi, maka untuk mencapainya pengguna sering mencari momen dimana harga sedang turun, mendapat diskon, menabung, memilih series yang sudah lalu, atau membeli barang bekas (second).

"Yang aku beli bukan seies yang terbaru, sengaja mencari yang sudah lalu agar harga lebih murah. Itupun aku masih harus nabung." - X.

\section{Apple Watch Sebagai Bagian Dalam Gaya Hidup Milenial}

Pada seri terbaru Apple Watch yaitu Series 5, terdapat 18 fitur yang dapat dimanfaatkan pengguna, seperti GPS/GNSS, kompas, barometric altimeter, tahan terhadap air, electrical heart sensor (ECG app), sensor jantung optik generasi kedua, panggilan darurat internasional, panggilan darurat SOS, akselerometer, giroskop, sensor cahaya sekitar, pengeras suara, mikrofon, Apple Pay, dan GymKit. Menurut Allison dan Smith (2020) terdapat 63 kegiatan yang dapat pengguna lakukan dengan memanfaatkan fitur-fitur dalam Apple Watch, diantaranya melacak kondisi kesehatan dan olahraga; menujukkan arah; menerima telepon 
dan menjawab pesan; mendengarkan musik dan podcast; perintah siri (alarm, pengatur waktu dan pengingat); dan pembayaran.

Informan menyatakan bahwa fitur-fitur Apple Watch yang banyak digunakan adalah aplikasi yang terkait dengan pekerjaan mereka, seperti notifikasi; pembaca pesan, email, dan foto; siri (alarm, pengingat); serta menerima telepon.

Terkait fitur kesehatan yang kaya ragam dalam Apple Watch, tidak terlalu dimanfaatkan secara maksimal. Notifikasi dan pengingat untuk sesi pernapasan (breath) dan bergerak fisik sederhana dianggap sangat membantu untuk mengingatkan agar bergerak dan berlatih fisik. Fitur kesehatan lain diakui belum digunakan dan tidak berpengaruh banyak dalam mendukung gaya hidup sehat karena belum dimanfaatkan dengan baik.

"Karena memang memupuni untuk mendukung fungsi kerja iPhone, aplikasi yang banyak kami manfaatkan tentu terkait pekerjaan, seperti untuk notifikasi dan remainder. Untuk aplikasi lain jarang sekali dipakai. Dipakai kalau lagi iseng atau ingat saja" - W.

\section{Manfaat Internet of Things Dalam Apple Watch Sebagai Gaya Hidup Milenial}

Menurut Malik, dkk. (2019) terdapat empat manfaat dari penggunaan IoT, yaitu:

1. Access of Data

IoT memberikan kesempatan untuk akses data dari berbagai sumber, secara real-time, dan tidak terbatas oleh lokasi. Manfaat dari IoT ini memberikan efisiensi waktu dan kemudahan. Informan menilai kualitas fitur dalam Apple Watch dinilai lebih unggul dibanding produk lain. Seperti GPS, memori, dan kecepatan internet dinilai baik untuk digunakan dimana saja dan dalam berbagai kondisi.

\section{Connectivity}

Perangkat IoT yang terhubung dalam jaringan langsung memungkinkan komunikasi yang lebih baik, tranparan, dan mengurangi ketidak efisienan. Dalam penerapan IoT terdapat proses di mana mesin akan bekerja satu sama lain yang menghasilkan kinerja yang lebih efektif dan baik, dan cepat. Hasil penelitian menunjukkan bahwa informan merasa puas dengan akses data pada Apple Watch sangat baik, terutama jika mengikuti series terbarunya. Kemampuan sinkronasi dengan iPhone menjadi alasan utama keunggulan dari Apple Watch.

\section{Time Saving}

IoT memungkinkan pemograman pekerjaan yang dapat menentukkan kapan dibutuhkan dan kapan harus selesai. Pemograman perangkat IoT membuat penggunanya dapat menghemat waktu dan energi. Informan menunjukkan bahwa dengan adanya Apple Watch sebagai pendukung kerja iPhone, sangat bermanfaat dalam mempersingkat waktu kerja mereka. Mereka dengan mudah melakukan review seperti pesan dan email, dan bahkan menerima telpon dengan Apple Watch dari pergelangan tangan mereka.

\section{Expenditure Effective}

Komunikasi dengan perangkat elektronik melalui jaringan internet membantu individu dalam pekerjaan sehari-harinya. IoT memudahkan transfer data ke jaringan yang terhubung sehingga menghemat waktu dan uang. Selain itu IoT membuat informasi ditransmisikan lebih cepat dengan energi yang dilakukan lebih sedikit. Informan menilai hadirnya Apple Watch sangat efektif dengan semakin berkembangnya berbagai fitur dan tampilan yang minimalis. Kegiatan terkait pekerjaan, belanja dan pembayaran, serta terhubung (sinkronasi) dengan produk Apple lainnya dpaat dilakukan dengan Apple Watch. 
Lorinsa, Dian. Apple Watch: Wearable Internet of Things (WloT) Dalam Gaya Hidup Milenial

Kelemahan Internet of Things Dalam Apple Watch Sebagai Gaya Hidup Milenial

Studi yang telah dilakukan oleh Malik, dkk. (2019) terdapat enam ketindak untungan atau ancaman yang ditemui dalam menggunakan IoT, yaitu privacy atau security, complexity, dependency, business model, society, dan regulatory standards. Namun peneliti hanya akan membahas empat diantaranya kecuali business model dan regulatory standards, karena tidak berkaitan dengan pengguna Apple Watch.

1. Privacy atau Security

Salah satu masalah besar IoT adalah privasi. Hal ini muncul karena semua informasi harus dienkripsi sehingga memungkinkan terjadinya pertukaran informasi pribadi yang rahasia yang dapat disalah gunakan oleh pihak lain. Selain itu setiap perangkat terhubung di seluruh dunia melalui internet memiliki risiko kehilangan data yang penting. Informan menilai bahwa mereka cukup percaya dengan produk Apple dibandingkan dengan produk lainnya. Mereka menilai produk Apple sangat memilih untuk disinkronasikan dengan produk lainnya, sehingga dinilai aman dari pencurian data dan masalah lainnya.

\section{Complexity}

Sistem dan jaringan menjadi Pundak utama teknologi IoT. Terdiri dai berbagai sistem dan jaringan membuat IoT terlihat kompleks atau rumit untuk digunakan. Apabila penggunanya belum memiliki pemahaman tentang tata cara penggunaaan perangkat IoT secara benar, maka memungkikan terjadi kerusakan atau kesalah input informasi pada sistem dan jaringan. Informan menyatakan pada awal pemakaian memang Apple Watch cukup rumit digunakan dan membutuhkan waktu untuk memahami cara kerjanya. Selain itu kadang terdapat ganguan untuk terhubung dengan perangkat lainnya, terutama perangkat lain diluar produk Apple.

\section{Dependency}

Perangkat IoT dapat dibilang telah menjadi pelengkap dalam setiap aktivitas individu seharihari. Tidak ada keraguan bahwa teknologi mendominasi cara hidup kita dan mencerminkan ketergantungan manusia terhadap teknologi. Jika ada kerusakan pada sistem, kemungkinan berdampak juga pada perangkat yang terhubung. Secara langsung atau tidak langsung, kerusakan tersebut akan memengaruhi kehidupan individu yang bergantung padanya. Hasil penelitian menunjukkan bahwa informan belum memiliki kebergantungan yang tinggi dengan Apple Watch. Mereka menyatakan masih lebih kesulitan apabila terjadi kerusakan pada iPhone dibandingkan Apple Watch.

\section{KESIMPULAN}

Pemanfaatan Internet of Things (IoT) pada gaya hidup generasi Milenial memang belum hingga tahap berkelanjutan, seperti penerapan smart living, smart home, smart energy, dan sebagainya. Hal ini sesuai dengan penelitian sebelumnya yang menunjukkan bahwa generasi Milenial memiliki keterbatasan dalam hal kepemilikan (ownership) akan tempat tinggalnya, serta pemahaman yang dalam akan teknologi, membuat mereka lebih berhati-hati dalam menggunakan produk IoT. Namun, IoT pada gaya hidup generasi Milenial lebih kepada penggunaan smart product dalam hal ini pada mode dan aksesoris, seperti smart watch. Hasil penelitian menunjukkan bahwa interaksi sosial dan kesadaran untuk memulai gaya hidup sehat menjadi alasan mereka memanfaatkan perangkat IoT dalam bentuk mode dan aksesoris. Smart watch yang merupakan bentuk wearable device, menjadi benda sekunder yang mereka butuhkan sebagai pelengkap fungsi ponsel mereka.

Dalam penelitian ini menunjukkan alasan informan menggunakan Apple Watch didorong kebutuhan untuk mendukung fungsi kerja dan kebutuhan untuk kemudahan sinkronisasi dengan ponsel yang mereka gunakan, yaitu iPhone. Kemudahan sinkronisasi dengan perangkat Apple lainnya dan kualitas dari fitur yang diberikan memberikan kepuasan informan dalam merasakan manfaat IoT dalam Apple Watch. Meski dinilai cukup kompleks 
dan rumit pada awal penggunaan, tetapi informan menilai produk Apple Watch tidak mengalami masalah terkait privasi dan keamanan. Selain itu, informan masih memiliki kebergantunagn tinggi pada iPhone dibandingkan Apple Watch, yang mereka nilai hanya sebagai aksesoris atau pendukung kerja.

\section{DAFTAR PUSTAKA}

Abdullah, M. A. M. (2015). Innovation Management and New Product Development: Apple Watch Analysis. R\&D Management. https://doi.org/10.1111/j.14679310.2009.00551_1.x

Allison, C. (2020). 53 Apple Watch tips and features: become a smartwatch ninja. Diambil 20 Juli 2020, dari https://www.wareable.com/apple/apple-watch-tips-and-tricks-iwatch7383

Anggraini, N., Kaburuan, E. R., Wang, G., \& Jayadi, R. (2019). Usability study and users' perception of smartwatch: Study on Indonesian customer. Procedia Computer Science, 161,1266-1274. https://doi.org/10.1016/j.procs.2019.11.241

APJII. (2019). Penetrasi dan Perilaku Pengguna Internet Indonesia. Apjii.

Apple.com. (2020a). Health on Apple Watch. Diambil 20 Juli 2020, dari https://www.apple.com/healthcare/apple-watch/

Apple.com. (2020b). Notifications. Diambil 20 Juli 2020, dari https://developer.apple.com/design/human-interfaceguidelines/watchos/overview/notifications/

Apple. (2017). Apple Inc.Form 10-K For the Fiscal Year Ended September 30, 2017. Apple Inc. https://doi.org/10.1016/b978-0-12-804444-5.00023-4

Avystem.com. (2019). What is Internet of Things (IoT)? Everything you Need to Know. Diambil 20 Juli 2020, dari https://www.avsystem.com/blog/what-is-internet-of-thingsexplanation/

Bhuvaneswari, V., \& Porkodi, R. (2014). The internet of things (IOT) applications and communication enabling technology standards: An overview. Proceedings - 2014 International Conference on Intelligent Computing Applications, ICICA 2014, (October 2017), 324-329. https://doi.org/10.1109/ICICA.2014.73

CHAN, C. (2019). Everything the Apple Watch GPS-only can do without an iPhone. Diambil 20 Juli 2020, dari https://www.imore.com/heres-what-apple-watch-can-do-withoutiphone

Cipriani, J. (2017). What you need to know about GPS and the Apple Watch Series 2. Diambil 20 Juli 2020, dari https://www.cnet.com/how-to/what-you-need-to-know-about-gpsand-the-apple-watch-series-2/

Dassault Systèmes. (2017). Internet of Things in the Enterprise. Dassault Systèmes. Massachusetts. Diambil dari https://www.3ds.com/fileadmin/Industries/Consumergoods-retail/pdf/whitepapers/iot-in-fashion-cgr-whitepaper.pdf

Denzin, N. K., \& Lincoln, Y. S. (2008). Introduction: The Discipline and Practice of Qualitative Research. In Handbook of Qualitative Research. In N. K. Denzin \& Y. S. Lincoln (Ed.), The Sage Handbook of Qualitative Research (Fifth, hal. 1-29). London: SAGE Publications Inc.

DeVaney, S. A. (2015). Understanding the Millennial Generation. Journal of Financial Service Professionals, 69(6), 11-14.

Gruman, G. (2014). Apple Watch: The Internet of things' new frontier. 
Hiremath, S., Yang, G., \& Mankodiya, K. (2014). Wearable Internet of Things: Concept, Architectural Components and Promises for Person-Centered Healthcare, (January). https://doi.org/10.4108/icst.mobihealth.2014.257440

Jensen, M. (2007). Defining lifestyle . Environmental Sciences, 4(2), 63-73. https://doi.org/10.1080/15693430701472747

Khair, F. (2015). Sistem Jaringan Computer Based Test. Jurnal Ilmiah Teknologi Informasi, $\operatorname{IV}(3), 62-66$.

Kumari, P., Lopez-Benitez, M., Lee, G. M., Kim, T. S., \& Minhas, A. S. (2017). Wearable Internet of Things - From human activity tracking to clinical integration. Proceedings of the Annual International Conference of the IEEE Engineering in Medicine and Biology Society, EMBS, 2361-2364. https://doi.org/10.1109/EMBC.2017.8037330

Kusumo, A. N. D. (2018). Pengaruh Brand Image dan Brand Trust Terhadap Niat Beli Apple Watch. Bandung.

Lundquist, C. (2016). Location of things: Why location matters in IoT. Diambil 20 Juli 2020, dari https://internetofthingsagenda.techtarget.com/blog/IoT-Agenda/Location-ofthings-Why-location-matters-in-IoT

Malik, A., Magar, A. T., Verma, H., Singh, M., \& Sagar, P. (2019). A detailed study of an internet of things (Iot). International Journal of Scientific and Technology Research, 8(12), 29892994.

Mauliansyah. (2016). The Social And Political Aspects of New Media (Menelusuri Jejak Kesadaran dan Tindakan Kolektif Massa). Source: Jurnal Ilmu Komunikasi.

Mauliansyah, Mursyidin. (2018). Tradisi Penelitian Ict4d: Tinjauan Tentang Historisitas, Proliferasi, Dan Proyeksi Masa Depan. Source: Jurnal Ilmu Komunikasi.

Nolin, J., \& Olson, N. (2016). The Internet of Things and convenience. Internet Research, 26(2), 360-376. https://doi.org/10.1108/IntR-03-2014-0082

Rghioui, A., \& Oumnad, A. (2017). Internet of things: Surveys for measuring human activities from everywhere. International Journal of Electrical and Computer Engineering, 7(5), 2474-2482. https://doi.org/10.11591/ijece.v7i5.pp2474-2482

Ridzuan, A. R. bin, Karim, R. A., Marmaya, N. H., Razak, N. A., Khalid, N. K. N., \& Yusof, K. N. M. (2018). Public Awareness towards Healthy Lifestyle. International Journal of Academic Research in Business and Social Sciences, 8(10), 927-936. https://doi.org/10.6007/ijarbss/v8-i10/4790

Sammut-Bonnici, T. (2015). Brand and Branding. Wiley Encyclopedia of Management, 6(January 2015), 1-3. https://doi.org/10.1002/9781118785317.weom120161

Shin, D. H., \& Jin Park, Y. (2017). Understanding the Internet of Things ecosystem: multi-level analysis of users, society, and ecology. Digital Policy, Regulation and Governance , 19(1), 77-100. https://doi.org/10.1108/DPRG-07-2016-0035

Siradj, Y. (2016). Potensi Smartwatch untuk Kesehatan. Telekontran, 4(1), 35-41.

Strother, N. (2017). IoT And Millennials. Diambil 20 Juli 2020, dari https://www.forbes.com/sites/pikeresearch/2017/03/24/iot-andmillennials/\#5db3e9d67ff3

Support.apple.com. (2020). Use the Activity app on your Apple Watch. Diambil 20 Juli 2020, dari https://support.apple.com/en-us/HT204517

Te.com. (2020). IoT Sensors. Diambil 20 Juli 2020, dari https://www.te.com/usaen/industries/sensor-solutions/applications/iot-sensors.html 
Wen, D., Zhang, X., \& Lei, J. (2017). Consumers' perceived attitudes to wearable devices in health monitoring in China: A survey study. Computer Methods and Programs in Biomedicine, 140, 131-137. https://doi.org/10.1016/j.cmpb.2016.12.009

World Health Organization. (2015). Healthy living : what is a healthy lifestyle? The Institutional Repository for Information Sharing (IRIS), 24. Diambil dari https://apps.who.int/iris/bitstream/handle/10665/108180/EUR_ICP_LVNG_01_07_0 2.pdf? sequence $=1 \&$ isAllowed $=y$

Zeki, A. M., Ramadan, A. M., Zeb, F. K., \& Ibrahim, M. (2018). Impact of life-style on health and physical capability: A data mining approach. ACM International Conference Proceeding Series, 2018-March(11), 119-124. https://doi.org/10.1145/3177148.3180101 